\title{
In Vitro Activity of Linezolid against Clostridium difficile
}

\author{
T. Peláez, R. Alonso, * C. Pérez, L. Alcalá, O. Cuevas, and E. Bouza \\ Microbiology and Infectious Diseases Service, Hospital General Universitario “Gregorio Marañón,” Madrid, Spain
}

Received 6 September 2001/Returned for modification 30 December 2001/Accepted 4 February 2002

\begin{abstract}
We examined the in vitro activity of linezolid against Clostridium difficile, including isolates with reduced

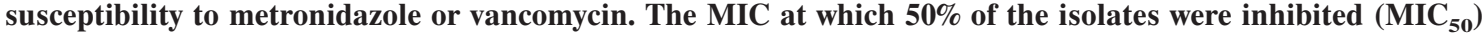
and $\mathrm{MIC}_{90}$ were 0.5 and $2 \mu \mathrm{g} / \mathrm{ml}$, respectively (range, 0.03 to $4 \mu \mathrm{g} / \mathrm{ml}$ ). MICs were always $\leq 4 \mu \mathrm{g} / \mathrm{ml}$, and thus, all isolates were considered susceptible.
\end{abstract}

Clostridium difficile is a major cause of infectious diarrhea and pseudomembranous colitis in hospitalized patients $(2,11$, $14)$, and it may also be an important cause of communityacquired diarrhea $(13,21)$.

Metronidazole and vancomycin are the drugs of choice for the treatment of $C$. difficile-associated diarrhea (CDAD), but new therapeutic options are urgently needed for several reasons, including high recurrence rates (1). Furthermore, vancomycin is quite expensive and ecologically undesirable (22). In recent years, the emergence of strains for which MICs of either metronidazole (12, 25; T. Peláez, L. Alcalá, L. MartínezSánchez, P. Muñoz, J. M. García-Lechuz, M. RodríguezCréixems, and E. Bouza, Abstr. 38th Intersci. Conf. Antimicrob. Agents Chemother., abstr. E-173, 1998; T. Peláez, R. Sánchez, R. Blázquez, P. Catalán, P. Muñoz, and E. Bouza, Abstr. 34th Intersci. Conf. Antimicrob. Agents Chemother., abstr. E34, 1994) or vancomycin (7) are high has been reported by us and by other groups.

Linezolid, is the first of a new class of antibacterial drugs, the oxazolidinones (9), and has inhibitory activity against a broad range of gram-positive aerobic cocci, including methicillin-resistant Staphylococcus aureus, glycopeptide-intermediate $S$. aureus, vancomycin-resistant enterococci, and penicillin-resistant Streptococcus pneumoniae (18). The drug also shows activity against certain anaerobes, but information on activity against C. difficile is very scarce $(8,18)$.

Our study examines the in vitro activity of linezolid against C. difficile, with a special interest in those strains which are resistant to metronidazole or which have reduced susceptibility to vancomycin, in order to assess the potential utility of this new agent in the treatment of CDAD.

We tested a total of 115 nonduplicate clinical isolates of toxigenic $C$. difficile selected from those obtained over a 9-year period (1993-2001) in our laboratory. C. difficile isolates were identified by standard procedures (16). The demonstration of toxin production was carried out, either directly from fecal samples or on isolated strains $(5,23)$, by the observation of the specific cytopathic effect on MRC-5 cells, as previously described $(16,20)$. The strain selection included 6 isolates which

\footnotetext{
* Corresponding author. Mailing address: Servicio de Microbiologia Claínica y Enfermedades Infecciosas, Hospital General Universitario "Gregorio Marañon," C/Dr. Esquerdo, 46, 28007 Madrid, Spain. Phone: 34-91-5868793. Fax: 34-91-5044906. E-mail: ralonso@microb net.
}

were resistant to metronidazole (1 inhibited at an MIC of 32 $\mu \mathrm{g} / \mathrm{ml}$ and 5 for which MICs were $\geq 64 \mu \mathrm{g} / \mathrm{ml}$ ) and 12 isolates with decreased susceptibility to vancomycin ( 7 for which the MIC was $4 \mu \mathrm{g} / \mathrm{ml}$ and 5 for which the MIC was $16 \mu \mathrm{g} / \mathrm{ml}$ ).

The active substance of linezolid was kindly provided by Pharmacia \& Upjohn, Inc. (Kalamazoo, Mich.). The antimicrobial agent was prepared and stored following the manufacturer's instructions. Antimicrobial susceptibility testing was performed by the agar dilution method, on Brucella agar (Oxoid; Hampshire, United Kingdom), according to guidelines of the National Committee for Clinical Laboratory Standards (17). Reference strains, Bacteroides fragilis ATCC 25285 and Bacteroides thetaiotaomicron ATCC 29741, were always included as controls to monitor antimicrobial susceptibility testing. A collection strain of $C$. difficile (ATCC 9689) was always included to assess reproducibility of the assay results. The susceptibility breakpoint for linezolid was considered to be $\leq 4$ $\mu \mathrm{g} / \mathrm{ml}(3,19)$.

The linezolid MICs at which 50 and $90 \%$ of the 115 assayed C. difficile isolates were inhibited were 0.5 and $2 \mu \mathrm{g} / \mathrm{ml}$, respectively. The MIC range was 0.03 to $4 \mu \mathrm{g} / \mathrm{ml}$. Linezolid MICs corresponding to $C$. difficile isolates resistant to metronidazole or with a decreased susceptibility to vancomycin were not different from those for the susceptible isolates (Table 1). MICs for all assayed isolates were $\leq 4 \mu \mathrm{g} / \mathrm{ml}$, and thus, all isolates were considered susceptible to linezolid.

In vitro susceptibility tests with $C$. difficile are not performed routinely in microbiology laboratories, since the first-line drugs, metronidazole and vancomycin, have been considered universally active against the microorganism (10). At present, there are reports of a reduction in susceptibility to metronidazole and vancomycin $(7,12,25$; T. Peláez et al., 38th ICAAC; T. Peláez et al., 34th ICAAC). Our group has registered more than $6 \%$ resistance to metronidazole (MICs of $>16 \mu \mathrm{g} / \mathrm{ml}$ ), and more than $3 \%$ of our $C$. difficile isolates have shown reduced susceptibility to vancomycin (MICs, 8 to $16 \mu \mathrm{g} / \mathrm{ml}$ ) (T. Peláez et al., submitted for publication).

Although the National Committee for Clinical Laboratory Standards has not yet expressly proposed a susceptibility breakpoint for linezolid, most authors consider susceptible all isolates inhibited at MICs equal to or less than $4 \mu \mathrm{g} / \mathrm{ml}(3,4$, 6). The European Committee on Antimicrobial Susceptibility Testing of the European Society of Clinical Microbiology and Infectious Diseases has also recently recommended this breakpoint (19). 
TABLE 1. MIC of linezolid for the assayed C. difficile isolates

\begin{tabular}{lcccc}
\hline & \multicolumn{4}{c}{ MIC $^{b}$} \\
\cline { 2 - 5 } Isolate group $\left(n^{a}\right)$ & Range & $50 \%$ & $90 \%$ & $\begin{array}{c}\text { Geometric } \\
\text { mean }\end{array}$ \\
\hline Total (115) & $0.03-4$ & 0.5 & 2 & 0.550 \\
Susceptible to MTZ and VAN (97) & $0.03-4$ & 0.5 & 2 & 0.567 \\
Resistant to MTZ (6) & $0.03-1$ & 0.5 & 1 & 0.394 \\
Not susceptible to VAN (12) & $0.03-2$ & 0.5 & 2 & 0.540 \\
\hline
\end{tabular}

${ }^{a} n$, no. of isolates.

${ }^{b}$ MIC range, MICs at which 50 and $90 \%$ of isolates are inhibited, and geometric mean are given in micrograms per milliliter.

It is also worth discussing that MIC breakpoints are usually set for systemic infections and that they are based upon levels of antimicrobial agent in blood. In our work, levels in the colon seem to be much more interesting than levels in the circulation. For metronidazole and vancomycin, levels in the colon might be high enough even to kill resistant strains (MICs of 200 to $2,000 \mu \mathrm{g} / \mathrm{ml}$ for vancomycin). In the case of linezolid, although the drug is efficiently absorbed in the gastrointestinal tract, the amount of active substance recovered in feces can range from 5.3 to $16.9 \%$ of the administered doses (400 to 600 mg twice daily) (24).

This study (to our knowledge, the largest series of $C$. difficile isolates that has been tested for linezolid to date) showed universal in vitro activity of linezolid against $C$. difficile isolates which are susceptible and not susceptible to conventional drugs.

We are well aware that in vitro activity does not necessarily mean in vivo activity and that this is particularly true for CDAD (15). We also know that treatment with linezolid has a high cost and that not much information is available about possible disruption of enteric flora. Nevertheless, in our opinion, these are promising data, and we believe they can lead to further studies on the efficacy of linezolid in cases of CDAD in both animals and humans.

\section{REFERENCES}

1. Alonso, R., S. Gros, T. Pelaez, D. Garcia-de-Viedma, M. Rodriguez-Creixems, and E. Bouza. 2001. Molecular analysis of relapse vs re-infection in HIV-positive patients suffering from recurrent Clostridium difficile associated diarrhoea. J. Hosp. Infect. 48:86-92.

2. Barbut, F., G. Corthier, Y. Charpak, M. Cerf, H. Monteil, T. Fosse, A Trévoux, B. De Barbeyrac, Y. Boussougant, S. Tigaud, F. Tytgat, A. Sedallion, S. Duborgel, A. Collignon, M. E. Le Guern, P. Bernasconi, and J. C. Petit. 1996. Prevalence and pathogenicity of Clostridium difficile in hospitalized patients. A French multicenter study. Arch. Intern. Med. 156:14491454.

3. Biedenbach, D. J., and R. N. Jones. 1997. Disk diffusion test interpretive criteria and quality control recommendations for testing linezolid (U-100766) and eperezolid (U-100592) with commercially prepared reagents. J. Clin. Microbiol. 35:3198-3202.
4. Biedenbach, D. J., and R. N. Jones. 2001. In vitro activity of linezolid (U-100766) against Haemophilus influenzae measured by three different susceptibility testing methods. Diagn. Microbiol. Infect. Dis. 39:49-53.

5. Bouza, E., T. Pelaez, R. Alonso, P. Catalan, P. Munoz, and M. R. Creixems. 2001. 'Second-look' cytotoxicity: an evaluation of culture plus cytotoxin assay of Clostridium difficile isolates in the laboratory diagnosis of CDAD. J. Hosp. Infect. 48:233-237.

6. Cercenado, E., F. Garcia-Garrote, and E. Bouza. 2001. In vitro activity of linezolid against multiply resistant Gram-positive clinical isolates. J. Antimicrob. Chemother. 47:77-81.

7. Dworczynski, A., B. Sokó, and F. Meisel. 1991. Antibiotic resistance of Clostridium difficile isolates. Cytobios 65:149-153.

8. Edlund, C., H. Oh, and C. Nord. 1999. In vitro activity of linezolid and eperezolid against anaerobic bacteria. Clin. Microbiol. Infect. 5:51-53.

9. Fung, H. B., H. L. Kirschenbaum, and B. O. Ojofeitimi. 2001. Linezolid: an oxazolidinone antimicrobial agent. Clin. Ther. 23:356-391.

10. George, W. L., V. L. Sutter, E. J. Goldstein, S. L. Ludwig, and S. M. Finegold. 1978. Aetiology of antimicrobial-agent-associated colitis. Lancet i:802-803.

11. Gerding, D. N., S. Johnson, L. R. Peterson, M. E. Mulligan, and J. Silva, Jr. 1995. Clostridium difficile-associated diarrhea and colitis. Infect. Control Hosp. Epidemiol. 16:459-477.

12. Jang, S. S., L. M. Hansen, J. E. Breher, D. A. Riley, K. G. Magdesian, J. E. Madigan, Y. J. Tang, J. Silva, Jr., and D. C. Hirsh. 1997. Antimicrobial susceptibilities of equine isolates of Clostridium difficile and molecular characterization of metronidazole-resistant strains. Clin. Infect. Dis. 25(Suppl. 2):S266-S267.

13. Kyne, L., C. Merry, B. O'Connell, C. Keane, and D. O'Neill. 1998. Community-acquired Clostridium difficile infection. J. Infect. 36:287-288.

14. Lyerly, D. M., H. C. Krivan, and T. D. Wilkins. 1988. Clostridium difficile: its disease and toxins. Clin. Microbiol. Rev. 1:1-18.

15. McVay, C. S., and R. D. Rolfe. 2000. In vitro and in vivo activities of nitazoxanide against Clostridium difficile. Antimicrob. Agents Chemother. 44:2254-2258.

16. Murray, P., J. O. E. Baron, F. C. Pfaller, F. C. Tenover, and R. H. Yolken. 1995. Manual of clinical microbiology, 6th ed. American Society for Microbiology, Washington, D.C.

17. National Committee for Clinical Laboratory Standards. 2001. Methods for antimicrobial susceptibility testing of anaerobic bacteria. Approved standard-5th ed. NCCLS document M11-A5 (ISBN 1-56238-429-5). National Committee for Clinical Laboratory Standards, Wayne, Pa.

18. Perry, C. M., and B. Jarvis. 2001. Linezolid: a review of its use in the management of serious gram-positive infections. Drugs 61:525-551.

19. Philips, I., F. Baquero, A. Bryskier, F. Goldstein, J. Mouton, G. Schito, S. Sidorenko, B. Wiedeman, et al. 2000. Linezolid breakpoints. Clin. Microbiol. Infect. 7:283-284.

20. Rifkin, G. D., F. R. Fekety, and J. Silva, Jr. 1977. Antibiotic-induced colitis: implication of a toxin neutralised by Clostridium sordellii antitoxin. Lancet ii:1103-1106.

21. Riley, T. V., M. Cooper, B. Bell, and C. L. Golledge. 1995. Communityacquired Clostridium difficile-associated diarrhea. Clin. Infect. Dis. 20(Suppl. 2): S263-S265.

22. Roghmann, M. C., R. J. McCarter, Jr., J. Brewrink, A. S. Cross, and J. G. Morris, Jr. 1997. Clostridium difficile infection is a risk factor for bacteremia due to vancomycin-resistant enterococci (VRE) in VRE-colonized patients with acute leukemia. Clin. Infect. Dis. 25:1056-1059.

23. Sednaoui, P., B. el Mantih, and M. Cauwell. 1999. "Second look" at cytotoxin B of Clostridium difficile in the course of diarrhea associated with antibiotic therapy. Pathol. Biol. (Paris) 47:415-421.

24. Slatter, J. G., D. J. Stalker, K. L. Feenstra, I. R. Welshman, J. B. Bruss, J. P. Sams, M. G. Johnson, P. E. Sanders, M. J. Hauer, P. E. Fagerness, R. P. Stryd, G. W. Peng, and E. M. Shobe. 2001. Pharmacokinetics, metabolism, and excretion of linezolid following an oral dose of drug. Metab. Dispos. 29:1136-1145.

25. Wong, S. S., P. C. Woo, W. K. Luk, and K. Y. Yuen. 1999. Susceptibility testing of Clostridium difficile against metronidazole and vancomycin by disk diffusion and Etest. Diagn. Microbiol. Infect. Dis. 34:1-6. 